\title{
Neoadjuvant Treatment of Nonfunctioning Pancreatic Neuroendocrine Tumors with $\left[{ }^{177}\right.$ Lu-DOTA $^{0}$, Tyr $\left.^{3}\right]$ Octreotate
}

\author{
Esther I. van Vliet ${ }^{1}$, Casper H. van Eijck ${ }^{2}$, Ronald R. de Krijger ${ }^{3}$, Elisabeth J. Nieveen van Dijkum ${ }^{4}$, Jaap J. Teunissen ${ }^{1}$, \\ Boen L. Kam ${ }^{1}$, Wouter W. de Herder ${ }^{5}$, Richard A. Feelders ${ }^{5}$, Bert A. Bonsing ${ }^{6}$, Tessa Brabander ${ }^{1}$, Eric P. Krenning ${ }^{1}$, \\ and Dik J. Kwekkeboom ${ }^{1}$ \\ ${ }^{I}$ Department of Nuclear Medicine, Erasmus MC, University Medical Center, Rotterdam, The Netherlands; ${ }^{2}$ Department of Surgery, \\ Erasmus Michoacande Ocampo, University Medical Center, Rotterdam, The Netherlands; ${ }^{3}$ Department of Pathology, Erasmus \\ Michoacande Ocampo, University Medical Center, Rotterdam, The Netherlands; ${ }^{4}$ Department of Surgery, Academic Medical Center, \\ University of Amsterdam, Amsterdam, The Netherlands; ${ }^{5}$ Department of Internal Medicine, Erasmus MC, University Medical Center, \\ Rotterdam, The Netherlands; and ${ }^{6}$ Department of Surgery, Leiden University Medical Center, Leiden, The Netherlands.
}

Pancreatic neuroendocrine tumors (NETs) are rare neoplasms for which surgery has almost the only potential for cure. When surgery is not possible because of tumor size and vascular involvement, neoadjuvant treatment with $\left[{ }^{177} \mathrm{Lu}^{\mathrm{DOOTA}} \mathrm{A}^{0}, \mathrm{Tyr}^{3}\right]$ octreotate $\left({ }^{177} \mathrm{Lu}-\right.$ octreotate) may be an option. Methods: We studied 29 Dutch patients with a pathology-proven nonfunctioning pancreatic NET treated with ${ }^{177}$ Lu-octreotate. All patients had a borderline or unresectable pancreatic tumor (group 1) or oligometastatic disease (defined as $\leq 3$ liver metastases) (group 2). Progression-free survival (PFS) was analyzed using the Kaplan-Meier method and Cox proportional hazards modeling. Results: After the treatment with ${ }^{177} \mathrm{Lu}-$ octreotate, successful surgery was performed in 9 of 29 patients (31\%). Six patients had a Whipple procedure, 2 patients had a pylorus-preserving pancreaticoduodenectomy, and 1 patient had a distal pancreatectomy and splenectomy. The median PFS was 69 mo for patients with successful surgery and 49 mo for the other patients. For comparison, the median PFS in 90 other patients with a nonfunctioning pancreatic NET with more than 3 liver metastases or other metastases was 25 mo. Conclusion: Neoadjuvant treatment with ${ }^{177} \mathrm{Lu}$-octreotate is a valuable option for patients with initially unresectable pancreatic NETs.

Key Words: pancreatic neuroendocrine tumor; PRRT; [177LuDOTA ${ }^{0}, \mathrm{Tyr}^{3}$ ]octreotate; neoadjuvant treatment; surgery

J Nucl Med 2015; 56:1647-1653

DOI: 10.2967/jnumed.115.158899

$\mathbf{P}$

ancreatic neuroendocrine tumors (NETs) are rare neoplasms. Because they grow slowly, they account for approximately $1.3 \%-$ $2 \%$ of all pancreatic cancers in incidence $(1,2)$ but almost $10 \%$ in prevalence (1). Despite the indolent nature of NETs, survival of patients with metastatic disease is limited, being approximately $35 \%$ overall after 5 y $(3,4)$.

Received Apr. 6, 2015; revision accepted Jul. 30, 2015.

For correspondence contact: Esther I. van Vliet, Department of Nuclear Medicine, Erasmus MC, University Medical Center, 's Gravendijkwal 230, 3015 CE Rotterdam, The Netherlands.

E-mail: esthervanvliet@yahoo.com

Published online Aug. 13, 2015.

COPYRIGHT (C 2015 by the Society of Nuclear Medicine and Molecular Imaging, Inc.
In cases of metastatic disease, treatment options may include streptozocin-based chemotherapy $(5,6)$, chemotherapy with capecitabine and temozolomide (7), peptide receptor radionuclide therapy (PRRT), or, in the case of predominant liver disease, liver-directed therapies such as debulking surgery, embolization, chemoembolization, radioembolization, or radiofrequency ablation. Newer treatment options include sunitinib (Sutent; Pfizer Inc), a tyrosine kinase inhibitor (8), or everolimus (Afinitor; Novartis Pharmaceuticals), an inhibitor of mammalian target of rapamycin (9).

Surgery remains almost the only option with the potential to cure pancreatic NET patients but is often not possible because of either vascular involvement or the presence of distant metastases. A few case reports have described the use of PRRT as neoadjuvant treatment in patients with pancreatic NETs (10-14). Here, we describe our experience with $\left[{ }^{177} \mathrm{Lu}\right.$-DOTA $\left.^{0}, \mathrm{Tyr}^{3}\right]$ octreotate $\left({ }^{177} \mathrm{Lu}\right.$-octreotate) treatment of a large series of patients with nonfunctioning pancreatic NETs in a neoadjuvant setting with a long follow-up.

\section{MATERIALS AND METHODS}

\section{Patients}

From the Dutch patients at our institution between January 2000 and June 2011, we retrospectively selected those who had a pathologyproven nonfunctioning pancreatic NET, had completed treatment with ${ }^{177} \mathrm{Lu}$-octreotate (unless the patient died earlier or had clinically evident progressive disease during treatment), and had undergone minimally 2 follow-up CT scans (unless the patient died earlier or had progressive disease as the treatment outcome). Nonfunctioning pancreatic NETs were defined by the absence of a clinical syndrome caused by hormonal hypersecretion. Only Dutch patients were selected, because loss to follow-up is very limited in this patient group. Patients were divided into 2 groups: borderline or unresectable pancreatic tumor (group 1) and oligometastatic disease (defined as $\leq 3$ liver metastases) (group 2). All patients in group 2 had advanced pancreatic NETs with either borderline or unresectable primary tumors. For comparison, we also analyzed another group of patients with nonfunctioning pancreatic NETs with more than 3 liver metastases or other distant metastases (group 3).

In this study, nonfunctioning pancreatic NETs were staged according to the Varadhachary/Katz CT staging system $(15,16)$. Briefly, tumors with arterial (superior mesenteric artery, celiac axis, or common hepatic artery), abutment $\left(<90^{\circ}\right.$ contact), or venous (portal or 
TABLE 1

Baseline Characteristics of Patients With and Without Successful Surgery After ${ }^{177}$ Lu-Octreotate $(n=29)$

\begin{tabular}{|c|c|c|c|}
\hline Characteristic & Successful surgery & Unresectable & $P$ \\
\hline No. of patients & 9 & 20 & \\
\hline No. of men & 5 & 9 & 0.70 \\
\hline Mean age (y) & $52(41-71)$ & $56(32-81)$ & 0.46 \\
\hline Mean longest-diameter tumor at baseline $(\mathrm{mm})^{\star}$ & $72(36-100)$ & $69(21-120)$ & 0.79 \\
\hline \multicolumn{4}{|l|}{ Tumor uptake on ${ }^{177}$ Lu-octreotate } \\
\hline Equal to normal liver & 0 & 2 & 0.47 \\
\hline More than normal liver & 4 & 11 & \\
\hline More than kidneys & 5 & 7 & \\
\hline Previous therapy & 3 & 5 & 0.68 \\
\hline Octreotide & 0 & 3 & 0.53 \\
\hline Surgery & 3 & 4 & 0.64 \\
\hline Radiotherapy & 0 & 1 & 1.00 \\
\hline Chemotherapy & 0 & 0 & NA \\
\hline Median total administered dose (GBq) & $30.0(22.3-30.3)$ & $29.8(11.2-30.2)$ & 0.10 \\
\hline $\begin{array}{l}\text { Regression (complete response/partial response/minor } \\
\text { response) as treatment outcome }{ }^{\dagger}\end{array}$ & 8 & 11 & 0.11 \\
\hline Mean alkaline phosphatase level at baseline $(\mathrm{U} / \mathrm{L})^{\ddagger}$ & $470(210-954)$ & $383(134-1,109)$ & 0.74 \\
\hline \multicolumn{4}{|l|}{ Location of tumor } \\
\hline Pancreatic head & 8 & 15 & 0.63 \\
\hline Pancreatic body or tail & 1 & 5 & \\
\hline
\end{tabular}

*Data on longest-diameter pancreatic tumor were available for all patients with and 18/20 patients without successful surgery after

${ }^{177} \mathrm{Lu}$-octreotate (in 2 patients only liver metastases could be measured).

${ }^{\dagger}$ Confirmed response 3 mo after treatment according to Southwest Oncology Group solid tumor response criteria.

${ }^{\ddagger}$ In patients with elevated levels at baseline (normal level, $<120 \mathrm{U} / \mathrm{L}$ ).

$\mathrm{NA}=$ not applicable.

Data in parentheses are range.

superior mesenteric vein) involvement with short-segment occlusion and possible reconstruction were considered borderline-resectable. Tumors with more than $90^{\circ}$ arterial encasement with no technical option for reconstruction or venous occlusion, or with tumor thrombus over a long segment, were considered unresectable.

This study was part of an ongoing prospective study on patients with gastroenteropancreatic NETs treated with ${ }^{177} \mathrm{Lu}$-octreotate at the Department of Nuclear Medicine, Erasmus University Medical Center Rotterdam, which was approved by the local medical ethical committee. All patients gave written informed consent to participate in the study.

\section{Treatment}

$\left[\right.$ DOTA ${ }^{0}, \mathrm{Tyr}^{3}$ ] octreotate was obtained from BioSynthema. ${ }^{177} \mathrm{LuCl}_{3}$ was distributed by IDB-Holland. ${ }^{177} \mathrm{Lu}$-octreotate was locally prepared as described previously (17). Granisetron, $3 \mathrm{mg}$, was injected intravenously $30 \mathrm{~min}$ before the infusion of ${ }^{177} \mathrm{Lu}$-octreotate began. To reduce the radiation dose to the kidneys, an infusion of amino acids $(2.5 \%$ arginine and $2.5 \%$ lysine, $1 \mathrm{~L}$ ) was started $30 \mathrm{~min}$ before the administration of the radiopharmaceutical and lasted $4 \mathrm{~h}$. The radiopharmaceutical was coadministered using a second pump system. Cycle doses were $7.4 \mathrm{GBq}$, injected over $30 \mathrm{~min}$. The intended interval between treatments was 6-10 wk. Patients were treated up to a cumulative intended dose of 22.2-29.6 GBq. Routine hematology, liver, and kidney function tests were performed before each therapy cycle and at follow-up visits.

\section{In Vivo Measurements}

Tumor response was assessed according to the Southwest Oncology Group solid tumor response criteria (18) with the addition of the tumor response class minor response, pertaining to a decrease of $25 \%-50 \%$. Response categories had to be confirmed on a subsequent $\mathrm{CT}$ scan, except for progressive disease.

\section{Grading}

Tumors were classified according to the European Neuroendocrine Tumor Society-World Health Organization 2010 grading system $(19,20)$. The Ki-67 proliferative index was assessed according to standard procedures in 2,000 tumor cells (except in 4 patients) in areas with the highest nuclear labeling using the MIB1 antibody (Dako). $\mathrm{Ki}-67$ values were determined on biopsies and resection specimens obtained before the treatment with ${ }^{177} \mathrm{Lu}$-octreotate. Because these data were not available in 7 patients with successful surgery after ${ }^{177} \mathrm{Lu}$-octreotate, we decided to use the $\mathrm{Ki}-67$ values on the resection specimens obtained after ${ }^{177} \mathrm{Lu}$-octreotate in these patients to allow all patients with successful surgery to be included in the Cox proportional hazards analysis.

\section{Statistics}

Progression-free survival (PFS) and overall survival (OS) were calculated. June 1, 2011, was used as the cutoff date. PFS was defined as the time from the first treatment with ${ }^{177} \mathrm{Lu}$-octreotate until the time of progression (radiologic or clinical) or death from any cause. For 
PFS analysis, patients were censored if they showed no progression at the time of the last CT/MR imaging tumor assessment before the cutoff date or loss to follow-up. OS was defined as the time from the first treatment with ${ }^{177} \mathrm{Lu}$-octreotate until the date of death from any cause. For OS analysis, patients were censored if alive at the last date of follow-up before the cutoff date or loss to follow-up. PFS and OS analyses were performed using the Kaplan-Meier method, and the results were compared by the log-rank test. Univariate and multivariate Cox proportional hazards modeling was conducted to evaluate parameters predictive of PFS. To give more insight into survival after surgery, an update on survival until June 1, 2015, was performed for the operated patients. For comparison, the status of all patients in groups 1 and 2 was also updated until June 1, 2015.

Patients with and without surgery were compared using $\chi^{2}$ tests (or, if applicable, Fisher exact tests) for categoric variables or using independent $t$ tests or Mann-Whitney $U$ tests for continuous variables. Two-sided $P$ values were reported. Values lower than 0.05 were considered significant. The SPSS statistical package, version 15.0 (IBM), was used.

\section{RESULTS}

Two hundred fourteen patients with a nonfunctioning pancreatic NET were treated with ${ }^{177} \mathrm{Lu}$-octreotate in our institution between January 2000 and June 2011; 95 non-Dutch patients were excluded. Thus, 119 patients were evaluated. There were 54 men and 65 women. Their mean age was 55 y (range, 23-85 y). Group 1 comprised 15 patients; group 2, 14; and group 3, 90 (including 23 patients with a Whipple procedure/distal pancreatectomy before ${ }^{177} \mathrm{Lu}$-octreotate). Three patients, all in group 3, had the multiple endocrine neoplasia type 1 syndrome. Eleven patients were also treated with the drug capecitabine (Xeloda; Roche), according to a new treatment protocol as part of an ongoing randomized clinical trial as described previously (21); none of these had surgery after ${ }^{177} \mathrm{Lu}$-octreotate. None of the patients with successful surgery after ${ }^{177} \mathrm{Lu}$-octreotate developed a serious delayed toxicity after ${ }^{177} \mathrm{Lu}$-octreotate.

The tumor response at 3 mo after the last treatment with ${ }^{177} \mathrm{Lu}-$ octreotate was remission (complete response + partial response + minor response) in 72 of 119 patients (61\%), stable disease in $24(20 \%)$, and progressive disease in 21 (18\%). Two patients had an unknown tumor response.

Ki-67 values and World Health Organization grade at baseline were available for 77 patients. The median Ki-67 value was $6 \%$ (range, 1\%-50\%). Fifteen patients had a G1 tumor (Ki-67, 0\%$2 \%), 53$ patients a $\mathrm{G} 2$ tumor $(\mathrm{Ki}-67,>2 \%-20 \%)$, and 9 patients a G3 tumor (Ki-67, >20\%).

\section{Surgery After ${ }^{177}$ Lu-octreotate}

Surgery was successful in 9 of 29 patients (31\%). There were no significant differences in patient or tumor characteristics before ${ }^{177} \mathrm{Lu}$-octreotate between patients with and without successful surgery after ${ }^{177} \mathrm{Lu}$-octreotate (Table 1 ). All patients with successful surgery after treatment had a borderline or unresectable pancreatic tumor before treatment because of vascular involvement as judged by a surgeon with expertise in pancreatic surgery and a radiologist before the start of treatment. All patients were restaged after the treatment with ${ }^{177} \mathrm{Lu}$-octreotate by the same, abovementioned, surgeon.

In addition to the 9 successfully operated patients, an attempt at resection was made in another patient; however, peroperatively

TABLE 2

Patient, Tumor, and Surgical Characteristics of Patients with Successful Surgery After ${ }^{177}$ Lu-Octreotate

\begin{tabular}{|c|c|c|c|c|c|c|}
\hline $\begin{array}{c}\text { Patient } \\
\text { no. }\end{array}$ & Age $(y)$ & Sex & $\begin{array}{l}\text { Best } \\
\text { response }\end{array}$ & $\begin{array}{l}\text { Months from last } \\
\text { treatment to surgery }\end{array}$ & Type of surgery & Complications of surgery \\
\hline 1 & 60 & $M$ & SD & 8.6 & Whipple & Line sepsis \\
\hline 2 & 41 & $\mathrm{~F}$ & MR & 6.5 & $\begin{array}{l}\text { PPPD + thrombectomy } \\
\text { of portal vein and } \\
\text { end-to-end portal } \\
\text { anastomosis }\end{array}$ & None \\
\hline 3 & 42 & $\mathrm{M}$ & MR & 20.3 & Whipple & Urinary tract infection \\
\hline 4 & 71 & $\mathrm{~F}$ & PR & 24.1 & PPPD & None \\
\hline 5 & 54 & $\mathrm{M}$ & PR & 10.4 & Whipple & None \\
\hline 6 & 52 & M & PR & 13.7 & $\begin{array}{l}\text { Distal pancreatectomy }+ \\
\text { splenectomy }\end{array}$ & None \\
\hline 7 & 43 & M & PR & 7.3 & $\begin{array}{l}\text { Whipple and reconstruction } \\
\text { of portal vein with biograft }\end{array}$ & $\begin{array}{l}\text { Venous bypass occlusion, } \\
\text { wound infection, intraabdominal } \\
\text { abscess, and ileus }\end{array}$ \\
\hline 8 & 43 & $\mathrm{~F}$ & MR & 11.8 & $\begin{array}{l}\text { Whipple }+ \text { resection of } \\
\text { paraaortic lymph node }+ \\
\text { radiofrequency ablation } \\
\text { of liver lesion }\end{array}$ & $\begin{array}{l}\text { Intraabdominal abscess, infected } \\
\text { thrombus in jugular vein (central } \\
\text { venous line for total parental nutrition) }\end{array}$ \\
\hline 9 & 60 & $\mathrm{~F}$ & PR & 33.2 & Whipple & $\begin{array}{l}\text { Atrial fibrillation and fever due to fluid } \\
\text { collection behind left liver lobe; } \\
\text { wound infection }\end{array}$ \\
\hline
\end{tabular}

$\mathrm{SD}=$ stable disease; $\mathrm{MR}=$ minor response; PPPD = pylorus-preserving pancreaticoduodenectomy; $\mathrm{PR}=$ partial response 
TABLE 3

Characteristics of Resection Specimen and Follow-up of Patients with Successful Surgery After ${ }^{177}$ Lu-Octreotate

\begin{tabular}{|c|c|c|c|c|c|c|c|}
\hline \multirow[b]{3}{*}{$\begin{array}{l}\text { Patient } \\
\text { no. }\end{array}$} & \multicolumn{6}{|c|}{ Resection specimen } & \multirow[b]{3}{*}{ Follow-up until June 1, 2015} \\
\hline & \multicolumn{3}{|c|}{ Characteristics } & \multicolumn{3}{|c|}{ Treatment effects } & \\
\hline & $\begin{array}{l}\text { Margins } \\
\text { free }^{\star}\end{array}$ & $\begin{array}{l}\text { Lymph nodes } \\
\text { positive }(n)\end{array}$ & $\mathrm{Ki}-67$ & Necrosis & $\begin{array}{l}\text { Fibrosis } \\
\text { or sclerosis }\end{array}$ & Other & \\
\hline 1 & Yes & $4 / 4$ & $1 \%$ & + & + & $\begin{array}{l}\text { Hemorrhage, } \\
\text { perineural } \\
\text { infiltration }\end{array}$ & $\begin{array}{l}\text { Local recurrence } 22 \text { mo after Whipple; } \\
\text { extensive lymphadenopathy and } \\
\text { liver metastases } 31 \text { mo after } \\
\text { Whipple, SRS-negative; died } 33 \text { mo } \\
\text { after surgery }\end{array}$ \\
\hline 2 & No & $0 / 7$ & $50 \%$ & - & + & - & $\begin{array}{l}\text { Local recurrence and liver metastases } \\
8 \text { mo after surgery; commencement } \\
\text { of chemotherapy (cisplatin and } \\
\text { etoposide) because of rapid tumor } \\
\text { growth, PD after } 2 \text { cycles; died } \\
23 \text { mo after surgery }\end{array}$ \\
\hline 3 & Yes & $0 / 0$ & $8 \%$ & + & - & - & $\begin{array}{l}\text { Disease-free } 73 \text { mo after surgery; alive } \\
73 \text { mo after surgery; lost to follow- } \\
\text { up } 73 \text { mo after surgery }\end{array}$ \\
\hline 4 & Yes & $0 / 14$ & $1 \%$ & - & + & - & $\begin{array}{l}\text { Disease-free } 45 \text { mo after surgery; alive } \\
51 \text { mo after surgery }\end{array}$ \\
\hline 5 & Yes & $0 / 11$ & $1 \%$ & - & + & - & $\begin{array}{l}\text { Disease-free } 91 \text { mo after surgery; alive } \\
96 \text { mo after surgery }\end{array}$ \\
\hline 6 & No & $0 / 3$ & $1 \%$ & - & + & - & $\begin{array}{l}\text { Local recurrence and liver metastases } \\
48 \text { mo after surgery; after } 2 \text { extra } \\
\text { cycles, PR; PD } 2 \text { y later; after } 2 \text { extra } \\
\text { cycles, PR; PD } 1.5 \text { y later; after } \\
\text { everolimus, SD for } 2.5 \text { y; PD } \\
\text { recently, with sunitinib treatment } \\
\text { being considered; alive } 132 \text { mo after } \\
\text { surgery }\end{array}$ \\
\hline 7 & Yes & $0 / 4$ & $3 \%$ & - & + & Hemorrhage & $\begin{array}{l}\text { Liver and lymph node metastases } \\
56 \text { mo after surgery; after } 2 \text { extra } \\
\text { cycles, MR; radiofrequency ablation } \\
\text { of remaining liver metastasis; new } \\
\text { liver metastases and possible local } \\
\text { recurrence } 3 \text { y later; "wait and see" } \\
\text { for } 1 \text { y; recent growth of liver } \\
\text { metastases, with radiofrequency } \\
\text { ablation scheduled (combined } \\
\text { with CyberKnife [Accuray Inc.] } \\
\text { radiotherapy of local recurrence); } \\
\text { alive } 119 \text { mo after surgery }\end{array}$ \\
\hline 8 & No & $4 / 10$ & $1 \%$ & - & + & - & $\begin{array}{l}\text { Disease-free, alive, and lost to follow- } \\
\text { up } 7 \text { mo after surgery }\end{array}$ \\
\hline 9 & Yes & $1 / 5$ & $30 \%$ & - & + & $\begin{array}{l}\text { Vasoinvasion, } \\
\text { perineural } \\
\text { growth }\end{array}$ & $\begin{array}{l}\text { Liver and lymph node metastases } \\
14 \text { mo after surgery; after } 2 \text { extra } \\
\text { cycles, SD; PD } 1.5 \text { y later; after } \\
\text { treatment with long-acting } \\
\text { somatostatin analog, alive } 54 \text { mo } \\
\text { after surgery }\end{array}$ \\
\hline
\end{tabular}

${ }^{*} \mathrm{R} 0$ resection achieved.

$\mathrm{SRS}=\left[{ }^{111} \mathrm{In}-\mathrm{DTPA}^{0}\right]$ octreotide scintigraphy; PD = progressive disease; $\mathrm{PR}=$ partial response; $\mathrm{SD}=$ stable disease; $\mathrm{MR}=$ minor response. 


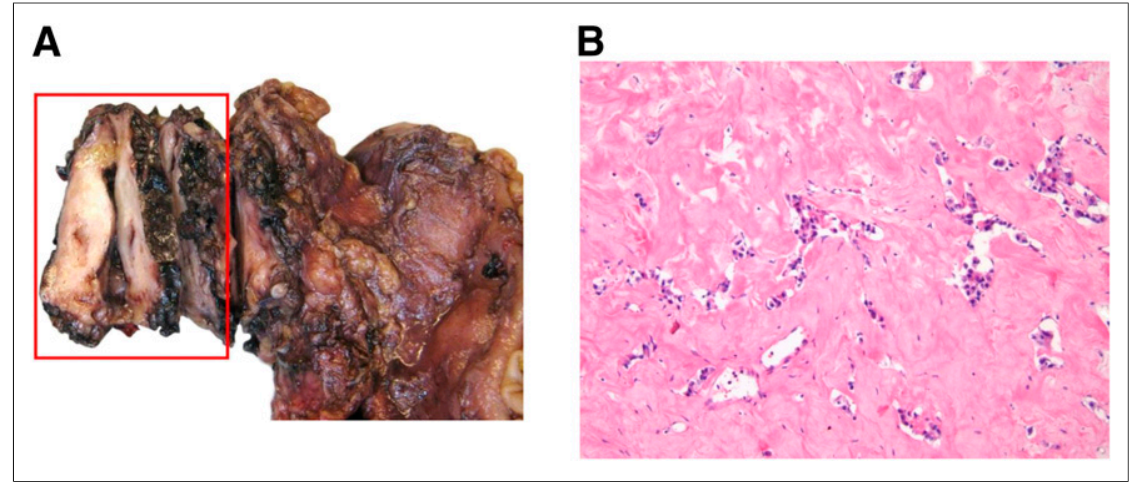

FIGURE 1. Macroscopic (A) and microscopic (B) appearance of pancreatic NET resection specimen from patient 4 , in whom ${ }^{177} \mathrm{Lu}$-octreotate treatment had extensive effect. (A) Hyalinization of tumor (red square) is seen macroscopically. Extensive degenerative changes are seen microscopically, including sclerosis, hyalinization, and few remaining viable tumor cells (hematoxylin and eosin, $\times 100$ ).

extensive tumor invasion into the caval vein was found. Lastly, another patient, who had a partial response after ${ }^{177} \mathrm{Lu}$-octreotate, and whose tumor was judged resectable after ${ }^{177} \mathrm{Lu}$-octreotate, refused surgery.

The patient and tumor characteristics of the 9 patients with successful surgery after ${ }^{177} \mathrm{Lu}$-octreotate are presented in Tables 2 and 3. Six patients had a Whipple procedure (1 in combination with a reconstruction of the portal vein with a biograft and 1 combined with a resection of a paraaortic lymph node and radiofrequency ablation of a liver lesion); 2 patients had a pylorus-preserving pancreaticoduodenectomy ( 1 in combination with a resection of a thrombus in the portal vein with an end-to-end portal anastomosis); and 1 patient had a distal pancreatectomy and splenectomy. The median time between the last treatment with ${ }^{177} \mathrm{Lu}$-octreotate and surgery was 12 mo (range, 7-33 mo). No surgical complications related to ${ }^{177} \mathrm{Lu}$-octreotate administration were observed. There was no perioperative mortality.

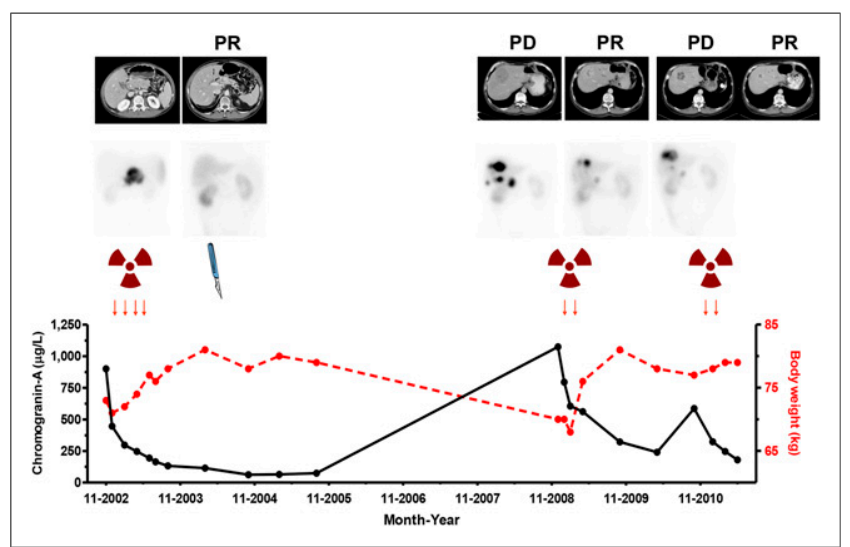

FIGURE 2. Clinical course of patient 6 , with NET in pancreatic tail. Shown are CT and $\left[{ }^{111}\right.$ In-DTPA ${ }^{0}$ octreotide scintigraphy images, serum chromogranin A levels, and body weight over time. Patient underwent distal pancreatectomy and splenectomy $14 \mathrm{mo}$ after regular ${ }^{177} \mathrm{Lu}-$ octreotate treatment. On local recurrence and metastasis to liver 48 mo after surgery, patient received another 2 cycles. On tumor progression 24 mo later, patient received another 2 cycles. Treatment cycles (arrows) brought about decreased chromogranin A level and increased body weight. $\mathrm{PD}=$ progressive disease; $\mathrm{PR}=$ partial response.
The pathologic characteristics of the surgical specimens are presented in Table 3. All resection specimens showed fibrosis/ sclerosis or necrosis as a treatment effect of ${ }^{177} \mathrm{Lu}$-octreotate (Fig. 1).

Five patients had a local recurrence or developed liver metastases 8, 14, 22, 48 , and 56 mo after surgery. The other 4 patients were disease-free with a median follow-up of 59 mo (range, 7-96 mo) after surgery ( 2 of these 4 patients were lost to follow-up 7 and 73 mo after surgery). Figure 2 shows the clinical course of a patient who had a local recurrence and liver metastases 48 mo after surgery. Two patients died 23 and 33 mo after surgery, and the other 7 patients were alive with a median follow-up of 73 mo (range, 7-132 mo) after surgery (again, 2 of these 7 patients were lost to follow-up 7 and 73 mo after surgery).

\section{Survival}

Thirteen patients in groups 1 and 2 had progression or died. The median PFS in the 29 patients in groups 1 and 2 was 55 mo (95\% confidence interval, 37-73). The median PFS was 69 mo for patients with successful surgery and 49 mo for the other patients. By comparison, the median PFS in the 90 patients in group 3 was 25 mo ( $P=0.01, \log$-rank test for the 3 groups $)$ (Fig. 3). The difference in PFS between the operated patients in groups 1 and 2 and the other patients in groups 1 and 2 was not significant $(P=0.22, \log$-rank test $)$. A total of 7 patients in groups 1 and 2 died. The median OS in the 29 patients in groups 1 and 2 was more than 105 mo. The median OS was more than 103 mo for patients with successful surgery and 60 mo for the other patients. By comparison, the median OS in the

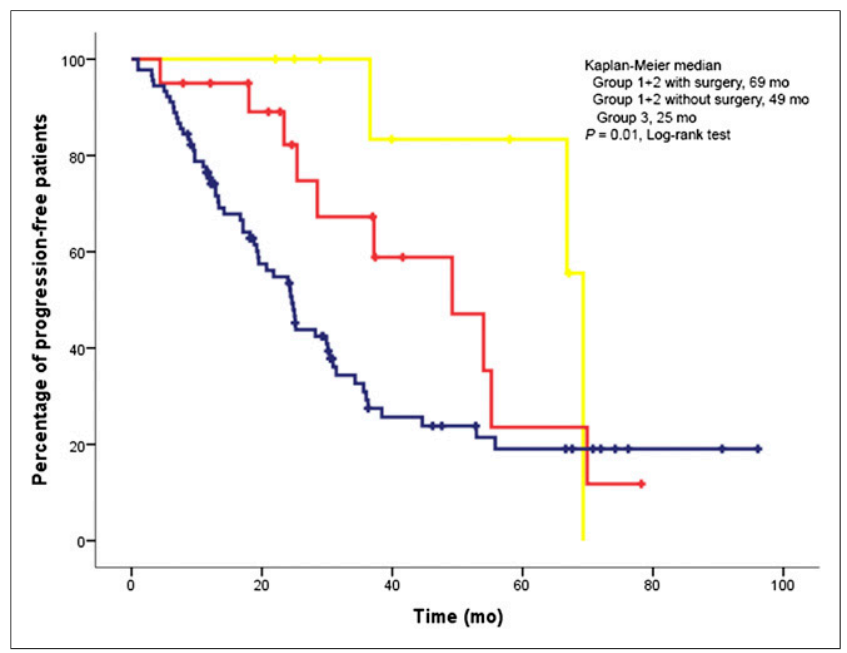

FIGURE 3. PFS in 29 patients with nonfunctioning pancreatic NETs. Median PFS was 69 mo for patients with successful surgery (yellow line) and 49 mo for the other patients (red line). By comparison, median PFS in 90 patients in group 3 (blue line) was 25 mo. Significant difference in median PFS among the 3 groups was observed $(P=0.01$, log-rank test). 
TABLE 4

Risk Factors for Progression in PFS on Univariate Analysis of Groups 1 and $2(n=29)$

\begin{tabular}{|c|c|c|c|c|}
\hline Variable & Median PFS (mo) & Hazard ratio & $95 \%$ confidence interval & $P$ \\
\hline Age (continuous variable) & & 1.05 & $1.01-1.10$ & 0.03 \\
\hline \multicolumn{5}{|c|}{ World Health Organization grade } \\
\hline 1 & $54(18-90)$ & 1.00 & & \\
\hline $2 / 3$ & $55(38-72)$ & 0.81 & $0.23-2.88$ & 0.74 \\
\hline \multicolumn{5}{|c|}{ Alkaline phosphatase baseline elevated } \\
\hline No & $69(48-90)$ & 1.00 & & \\
\hline Yes & $49(18-81)$ & 1.96 & $0.65-5.86$ & 0.23 \\
\hline \multicolumn{5}{|c|}{ Successful surgery after ${ }^{177}$ Lu-octreotate } \\
\hline No & $49(28-70)$ & 1.00 & & \\
\hline Yes & 69 (NA) & 0.44 & $0.12-1.66$ & 0.23 \\
\hline \multicolumn{5}{|l|}{ Sex } \\
\hline Female & $49(10-89)$ & 1.00 & & \\
\hline Male & $69(64-74)$ & 0.34 & $0.09-1.27$ & 0.11 \\
\hline Ki-67 (continuous variable) & & 0.95 & $0.79-1.14$ & 0.58 \\
\hline \multicolumn{5}{|c|}{ Baseline alkaline phosphatase (U/L) } \\
\hline$<120$ & $69(48-90)$ & 1.00 & & \\
\hline $120-500$ & $37(16-57)$ & 2.01 & $0.64-6.31$ & 0.23 \\
\hline$>500$ & 49 (NA) & 1.68 & $0.19-14.68$ & 0.64 \\
\hline \multicolumn{5}{|c|}{ Baseline chromogranin A ( $\mu \mathrm{g} / \mathrm{L})$} \\
\hline$<150$ & $55(36-75)$ & 1.00 & & \\
\hline $150-1,000$ & $67(20-113)$ & 1.20 & $0.33-4.31$ & 0.79 \\
\hline$>1,000$ & 23 (NA) & 7.57 & $0.56-103.10$ & 0.13 \\
\hline \multicolumn{5}{|c|}{$\begin{array}{l}\text { NA }=\text { not applicable. } \\
\text { Data in parentheses are } 95 \% \text { confidence interval. No multivariate analysis was performed because only } 1 \text { variable (i.e., age) had } \\
\leq 0.10 \text { and could be included in model. }\end{array}$} \\
\hline
\end{tabular}

90 patients in group 3 was $52 \mathrm{mo}(P=0.10, \log$-rank test for the 3 groups).

In groups 1 and 2, age was the only factor associated with progression or death at univariate analysis (Table 4). No multivariate analysis was performed because only 1 variable (i.e., age) had a $P$ value of less than or equal to 0.10 and could be included in the model.

The update on survival until June 1, 2015, showed that 12 nonoperated patients had progression or died whereas 5 operated patients had progression or died. Nine nonoperated patients died, whereas 2 operated patients died.

\section{DISCUSSION}

We found an encouraging rate of successful surgery in 9 of 29 neoadjuvantly treated patients with a pancreatic NET (31\%). There were no significant differences in baseline characteristics-which could potentially be used to select patients for surgery-between the operated and nonoperated patients in the neoadjuvantly treated group. Although we realize that some surgeons might deem most of our patients resectable upfront, we feel it is important that every patient who can be treated with PRRT in a neoadjuvant manner be evaluated by a surgeon for assessment of potential resectability of the tumor. Even patients with stable disease as the response outcome may be eligible for surgery, as was demonstrated in one patient in our series. This patient had a tumor size decrease of $22 \%$ after ${ }^{177} \mathrm{Lu}$-octreotate. Although this decrease was not enough to be recorded as a minor response, it was sufficient to resolve the vascular involvement, which had caused the tumor to be considered unresectable before ${ }^{177} \mathrm{Lu}$-octreotate treatment.

None of the patients considered for surgery showed progressive disease. In most patients there was an obvious response to PRRT and no more vascular resection was necessary during pancreaticoduodenectomy. Patients with extensive vascular involvement or venous portal/mesenteric thrombosis before PRRT developed sufficient venous collaterals during treatment. In most cases this was through the inferior mesenteric vein. These patients underwent resection with reconstruction of the portal and partial mesenteric veins, leaving the collateral circulation intact. Surgery after PRRT could be safely performed in all patients.

PRRT as neoadjuvant treatment in patients with pancreatic NETs has been described in a few case reports. Three patients received ${ }^{90}$ Y-based somatostatin analogs (10-12), and 2 patients ${ }^{177} \mathrm{Lu}$-based somatostatin analogs $(13,14)$. Although these case reports demonstrate the potential of PRRT in a neoadjuvant setting, follow-up after surgery was limited. The present study describes a group of patients with surgery after PRRT with a long follow-up, allowing us to report on survival.

Because of the retrospective nature of this study, an effect of selection bias on the operated patient group cannot be excluded. 
For example, in patients who have a comorbidity that precludes surgery, this comorbidity may be the reason for death, thus leading to a worse survival in the nonoperated patients. In our patient group, however, this seems unlikely, since none of the nonoperated patients had been denied surgery because of comorbidities. However, since resection was undertaken at a median of 12 mo after the last treatment, a better prognostic group might have been selected by the inherent behavior of the cancer. To demonstrate an effect on survival, ideally a prospective study should be undertaken in which patients who are eligible for surgery after ${ }^{177} \mathrm{Lu}-$ octreotate are randomized between surgery and no surgery. However, we deem such a study not ethical.

A limitation of this study is its retrospective nature. We are aware that because the cases were identified retrospectively, and definitions of resectable and unresectable are often subjective and surgeon-dependent, some cases may have been considered resectable in other centers, even without ${ }^{177} \mathrm{Lu}$-octreotate. However, the patients described in this study were all deemed unresectable before treatment with ${ }^{177} \mathrm{Lu}$-octreotate by a surgeon with expertise in pancreatic surgery and would not have been operated on in our center. Furthermore, this study showed that the approach of first ${ }^{177} \mathrm{Lu}$-octreotate and then surgery can be safely performed and can be considered in patients with a nonfunctioning pancreatic NET with limited tumor load. The treatment with ${ }^{177} \mathrm{Lu}$-octreotate might have led to less extensive surgery, possibly resulting in lower morbidity. We feel that our observations justify a prospective study on the neoadjuvant use of ${ }^{177} \mathrm{Lu}$-octreotate in patients with nonfunctioning pancreatic NETs, in which predefined criteria of tumor resectability should be incorporated.

\section{CONCLUSION}

Neoadjuvant treatment with ${ }^{177} \mathrm{Lu}$-octreotate is a valuable option for patients with initially unresectable pancreatic NETs. Our observations justify a prospective study on the neoadjuvant use of ${ }^{177} \mathrm{Lu}$-octreotate in patients with nonfunctioning pancreatic NETs.

\section{DISCLOSURE}

The costs of publication of this article were defrayed in part by the payment of page charges. Therefore, and solely to indicate this fact, this article is hereby marked "advertisement" in accordance with 18 USC section 1734 . No potential conflict of interest relevant to this article was reported.

\section{REFERENCES}

1. Yao JC, Eisner MP, Leary C, et al. Population-based study of islet cell carcinoma. Ann Surg Oncol. 2007;14:3492-3500.

2. Franko J, Feng W, Yip L, Genovese E, Moser AJ. Non-functional neuroendocrine carcinoma of the pancreas: incidence, tumor biology, and outcomes in 2,158 patients. J Gastrointest Surg. 2010;14:541-548.
3. Durante C, Boukheris H, Dromain C, et al. Prognostic factors influencing survival from metastatic (stage IV) gastroenteropancreatic well-differentiated endocrine carcinoma. Endocr Relat Cancer. 2009;16:585-597.

4. Scarpa A, Mantovani W, Capelli P, et al. Pancreatic endocrine tumors: improved TNM staging and histopathological grading permit a clinically efficient prognostic stratification of patients. Mod Pathol. 2010;23: 824-833.

5. Moertel CG, Lefkopoulo M, Lipsitz S, Hahn RG, Klaassen D. Streptozocindoxorubicin, streptozocin-fluorouracil or chlorozotocin in the treatment of advanced islet-cell carcinoma. N Engl J Med. 1992;326:519-523.

6. Kouvaraki MA, Ajani JA, Hoff P, et al. Fluorouracil, doxorubicin, and streptozocin in the treatment of patients with locally advanced and metastatic pancreatic endocrine carcinomas. J Clin Oncol. 2004;22:4762-4771.

7. Strosberg JR, Fine RL, Choi J, et al. First-line chemotherapy with capecitabine and temozolomide in patients with metastatic pancreatic endocrine carcinomas. Cancer. 2011;117:268-275.

8. Raymond E, Dahan L, Raoul JL, et al. Sunitinib malate for the treatment of pancreatic neuroendocrine tumors. $N$ Engl J Med. 2011;364:501-513.

9. Yao JC, Shah MH, Ito T, et al. Everolimus for advanced pancreatic neuroendocrine tumors. N Engl J Med. 2011;364:514-523.

10. Kaemmerer D, Prasad V, Daffner W, et al. Neoadjuvant peptide receptor radionuclide therapy for an inoperable neuroendocrine pancreatic tumor. World $J$ Gastroenterol. 2009;15:5867-5870.

11. Stoeltzing O, Loss M, Huber E, et al. Staged surgery with neoadjuvant ${ }^{90} \mathrm{Y}-$ DOTATOC therapy for down-sizing synchronous bilobular hepatic metastases from a neuroendocrine pancreatic tumor. Langenbecks Arch Surg. 2010;395: $185-192$.

12. Sowa-Staszczak A, Pach D, Chrzan R, et al. Peptide receptor radionuclide therapy as a potential tool for neoadjuvant therapy in patients with inoperable neuroendocrine tumours (NETs). Eur J Nucl Med Mol Imaging. 2011;38: 1669-1674.

13. Barber TW, Hofman MS, Thomson BN, Hicks RJ. The potential for induction peptide receptor chemoradionuclide therapy to render inoperable pancreatic and duodenal neuroendocrine tumours resectable. Eur J Surg Oncol. 2012;38: 64-71.

14. Ezziddin S, Lauschke H, Schaefers M, et al. Neoadjuvant downsizing by internal radiation: a case for preoperative peptide receptor radionuclide therapy in patients with pancreatic neuroendocrine tumors. Clin Nucl Med. 2012;37: $102-104$.

15. Varadhachary GR, Tamm EP, Abbruzzese JL, et al. Borderline resectable pancreatic cancer: definitions, management, and role of preoperative therapy. Ann Surg Oncol. 2006;13:1035-1046.

16. Katz MH, Pisters PW, Evans DB, et al. Borderline resectable pancreatic cancer: the importance of this emerging stage of disease. J Am Coll Surg. 2008;206:833846.

17. Kwekkeboom DJ, Bakker WH, Kooij PP, et al. [ ${ }^{177} \mathrm{Lu}-\mathrm{DOTAOTyr}$ ] comparison with [ ${ }^{111}$ In-DTPAo]octreotide in patients. Eur J Nucl Med. 2001;28: 1319-1325.

18. Green S, Weiss GR. Southwest Oncology Group standard response criteria, endpoint definitions and toxicity criteria. Invest New Drugs. 1992;10:239253.

19. Rindi G, Kloppel G, Alhman H, et al. TNM staging of foregut (neuro)endocrine tumors: a consensus proposal including a grading system. Virchows Arch. 2006;449: 395-401.

20. Rindi G, Arnold R, Bosman FT, et al. Nomenclature and classification of neuroendocrine neoplasms of the digestive system. In: Bosman FT, Carneiro F, Hruban RH, Theise ND, eds. WHO Classification of Tumours of the Digestive System. Lyon, France: IARC Press; 2010:13-14.

21. van Essen M, Krenning EP, Kam BL, de Herder WW, van Aken MO, Kwekkeboom DJ. Report on short-term side effects of treatments with ${ }^{177} \mathrm{Lu}$ octreotate in combination with capecitabine in seven patients with gastroenteropancreatic neuroendocrine tumours. Eur J Nucl Med Mol Imaging. 2008;35: $743-748$. 